\title{
Sentiments and Perceptions of Business Respondents on Social Media: an Exploratory Analysis
}

\author{
Vanessa Torres van Grinsven ${ }^{1}$ and Ger Snijkers ${ }^{2}$
}

\begin{abstract}
The perceptions and sentiments of business respondents are considered important for statistical bureaus. As perceptions and sentiments are related to the behavior of the people expressing them, gaining insights into the perceptions and sentiments of business respondents is of interest to understand business survey response. In this article we present an exploratory analysis of expressions in the social media regarding Statistics Netherlands. In recent years, social media have become an important infrastructure for communication flows and thus an essential network in our social structure. Within that network participants are actively involved in expressing sentiments and perceptions. The results of our analysis provide insights into the perceptions and sentiments that business respondents have of this national statistical institute and specifically its business surveys. They point towards the specific causes that have led to a positive or a negative sentiment. Based on these results, recommendations aimed at influencing the perceptions and sentiments will be discussed, with the ultimate goal of stimulating survey participation. We also suggest recommendations regarding social media studies on sentiments and perceptions of survey respondents.
\end{abstract}

Key words: Business survey communication; survey participation; response motivation; expressions; social media.

\section{Introduction}

In the Netherlands, Statistics Netherlands (hereinafter $\mathrm{SN}$ ) is responsible for publishing official statistics to be used in practice for policy making and scientific research. Data on a large variety of topics are collected and processed for the production of statistics. To obtain its data, SN established a policy on data collection a decade ago; the most recent update to this policy was carried out in 2011 (Snijkers et al. 2011). Although surveys are still an important way of collecting data, secondary data need to be used before a survey is considered. Secondary data include administrative data, and in the future will very likely also include big data (Groves 2011; Daas et al. 2013). This data collection strategy applies to both social and business statistics. One major driver in the implementation of this strategy was and still is the reduction of response burden, that is, the compliance costs for businesses. Over the last two decades, SN has reduced its actual response burden by about

${ }^{1}$ Faculty of Social Sciences, Utrecht University, Padualaan 14, 3584 CH, Utrecht; Statistics Netherlands, CBS-weg 11, 6412 EX, Heerlen, Netherlands. Email: torresvangrinsven@gmail.com

${ }^{2}$ Statistics Netherlands, CBS-weg 11,6412 EX, Heerlen, Netherlands. Email: gsks@cbs.nl

Acknowledgment: We would like to thank Marleen Verbruggen and Piet Daas of Statistics Netherlands for their contributions. Without their support this study would not have been possible. We would also like to thank the editors and the referees for their helpful comments. 
70 percent (Snijkers 2008). In addition to its responsibility for official national statistics, SN also has the task of producing European (community) statistics.

Some of the official business surveys request financial data, like the annual Structural Business Survey (SBS), but others request other kinds of data, for example, movements (the Traffic and Transport Surveys), ICT use within a company (the ICT survey), and international trade (International Trade Survey). Some businesses are sampled for multiple surveys, and for recurring surveys they receive a questionnaire for a number of waves, because of their importance for the statistics. On a yearly basis, about a million questionnaires are sent to businesses.

We know that some businesses are not fond of these surveys, but most of them comply. An important reason for compliance is the fact that most of these surveys are mandatory (Torres van Grinsven et al. 2014; Snijkers et al. 2013). In the Netherlands, sentiments about official business surveys sent out by SN have been expressed in traditional media, for instance in newspapers, and in publications by business organizations, among others. For example, in a 2006 publication of the Dutch Employers' Union in the provinces of Brabant and Zeeland (Brabants Zeeuwse Werkgeversvereniging) it is stated for example that for surveys "the costs outweigh the added value" (van Vroenhoven 2006, 23). Some businesses express their views on surveys by sending letters and e-mails to Statistics Netherlands, or contacting its help desk by phone. In the past, politicians have also expressed their sentiments on official business surveys.

Research on the sentiments of business respondents towards official business surveys is not new. At SN, Customer Satisfaction Surveys of respondents have been conducted to study these views (for an analysis of these data, see, Giesen 2012). An overview of (data on) these sentiments that concern the official business surveys conducted by Statistics Netherlands has been presented by Snijkers et al. (2007). These studies will be discussed in the concluding section of the present article.

Collecting and analyzing these sentiments has been cumbersome because the data needed to be collected from various sources. The gathering of the appropriate data that measured these sentiments was not self-evident for any of these sources. However, with the expanding usage of social media, data on perceptions and sentiments have become more readily available. Recent research estimates that around 60 percent of the Dutch population actively posts messages on social media (Daas and Puts 2014). The huge amount of Dutch messages (Coosto 2014) may thus be an interesting data source for the analysis of perceptions and sentiments of business survey respondents in the Netherlands, and might be an appropriate replacement for the data formerly used.

In this article we present the results of an analysis of expressions in social media by business respondents about SN, its business surveys and questionnaires. This analysis can be characterized as exploratory, as it is not used to test hypotheses, but to explore how many expressions have been posted on social media and the content of these messages. For this study, all available data (expressions in social media) within a specific period of time have been used, as we will discuss in Subsection 2.1. As such, this study can be characterized as an analysis of "organic" data, as opposed to "designed" data created by survey research (Groves 2011). Researching perceptions and sentiments through a survey, for example, is inherently different from the analysis we have done on social media data. The expressions in social media data can be genuinely defined as "texts": they are "words 
and images that have become recorded without the intervention of a researcher" (Silverman 2000, 825). In a survey or an interview, the researchers' preconceptions always strongly influence the categories of topics that are revealed. When the data analyzed are "texts" as defined by Silverman, it is much more likely that original participants' categories will be discovered.

This analysis indicates sentiments and perceptions respondents have of SN, or, in another words, meanings these respondents attribute to SN and its actions. In addition, it also provides insights into sources that cause these perceptions and sentiments. Analyzing these expressions in depth unveils both major irritations and positive attitudes, and this knowledge can in turn be used to improve the design of communication strategies and surveys in such a way that the perception businesses and business respondents have of a national statistical institute (hereinafter NSI) will be influenced in a positive way.

The sentiments and perceptions of business respondents are relevant to business surveys because it is proposed that these are related to survey participation, as well as the respondent's behavior when completing a questionnaire, via perceived response burden and the motivation to respond (as is discussed by Giesen 2012; Torres van Grinsven et al. 2014; Snijkers and Jones 2013; Willimack and Snijkers 2013; Haraldsen et al. 2013). Consequently, this affects the quality of the resulting survey data (see e.g., Wenemark et al. 2011; Haraldsen 2013) as well as the cost efficiency of survey data collection (Snijkers and Jones 2013). Blumer (1973) noted that human behavior results from a vast interpretive process in which people, both individually and collectively, guide themselves by defining and evaluating the objects, events and situations they encounter. This is another way of saying that business survey response behavior is affected by business respondents' interpretation of the NSI and the survey request - or the perception they have of the NSI and the survey request. Social media are used more and more to express these perceptions and sentiments. The internet and social media have developed into a new, vast communicative infrastructure and cultural forum (Jensen and Helles 2011), in which social actors as communicators become sources of information themselves (Jensen 2012) and are actively involved in expressing perceptions and images. Moreover, business survey respondents may be active on social media, which makes social media an interesting data source to explore when researching the perceptions and sentiments of business survey respondents, especially if one is interested in a better understanding of these respondents' behavior.

This study has two explorative research questions. The first question is: what can we find in the social media, and is the study of messages on social media useful for $\mathrm{SN}$ in understanding business respondents' views on SN and its surveys? Second, we aim at gaining insights into the content of these expressions: the perceptions or images they reflect, the sentiments expressed, and the causes for both positive and negative sentiments.

That is, first, we explored social media as a new kind of data source to find out if researching social media messages can lead to useful results; and second, we explored these expressions on social media to find out what sentiments and perceptions they reflect, and what the causes of these sentiments and perceptions are.

Based on the first research question, the following research objectives are discussed in this article: what is the number of expressions about $\mathrm{SN}$ and its surveys and questionnaires on social media and on web fora? Are there fluctuations in these numbers over time? 
The aim here is to see whether there is any connection with the dispatching of questionnaires or other events. The second research question led to the following research objectives: what are the sentiments, are they negative or positive in nature? Which perceptions (ideas or images) do business respondents have of $\mathrm{SN}$, its surveys and questionnaires as shown in these expressions? What aspects of the survey do these expressions relate to, and which aspects do people complain or write positively about?

\section{Data and Method}

\subsection{Data}

The data source used for this study is a database named Coosto, a social media monitor operating in the Netherlands. In this database, virtually all public posts in the Dutch language on Dutch social media, web fora and weblogs have been structurally collected and stored since January 2009 (Coosto 2014). Since August 2010 this has included all posts on Twitter, so-called "tweets". Currently, this database contains more than a billion entries, and each day about 3.2 million entries are added. At the time of data extraction (August 2012), more than 390,000 different social media channels were used, among which the most important were Twitter, Facebook, Hyves, and Google+. Studies of the content of Dutch Twitter messages - the dominant social medium in the Netherlands revealed that nearly 50 percent of the messages were composed of "pointless babble" (Daas et al. 2012). This makes the main problem in social media research discriminating the informative from the noninformative messages. The large share of the noninformative "babble" messages negatively affects the use of the more serious informative messages (Daas et al. 2013).

We addressed this problem by devising a restrictive search in the Coosto database, which resulted in a selection of posts to be analyzed. The selection was based on posts for the period January 2009-August 2012. Keywords for the search included a combination of different denotations of the NSI, and a set of survey-related keywords, like "survey", "questionnaire", "letter", "response", "fine", “obligation", "mandatory", "administrative burden", the name of major surveys, and so on. The resulting data set, however, still included a lot of "noise" and irrelevant records (see, Daas and Puts 2014, 26). We then restricted the posts to those strictly relevant to business respondents and business surveys. Double entries that resulted from the overlapping original sets of queries were taken care of. Entries from large news sites and Twitter and Facebook news accounts were left out, as our interest was on more personal sentiments and dialogues, stemming from business respondents themselves. The few posts or tweets by SN or the Dutch Ministry of Economic affairs were left out as well. Posts that clearly referred to household surveys (114 posts) and posts that did not clearly speak about business surveys (50 posts) were left out as well, as we were only interested in sentiments and perceptions of business respondents towards business surveys in particular. This resulted in 477 posts that were clearly about business surveys and written by business respondents; these posts were analyzed in this study. These procedures can be characterized as the selection of posts based on the relevance to our research objectives. The resulting data set of 477 posts can be defined as the population of public posts with regard to our research questions for the period 
January 2009-August 2012; furthermore, in our study no sample was drawn from this population and instead we analyzed the whole population.

\subsection{Methods of Analysis}

The selected posts were analyzed using a sequential two-step mixed-method design. First, a word count or "lexical analysis" was carried out, followed by a qualitative thematic analysis.

In a lexical analysis (also called "word counts" or "concordance analyses") a word list is created which can be seen as concentrated or distilled data (Tesch 1990, 138-139). This enables the exploration and objective identification of central themes in large bodies of text. The words from the word list are therefore clustered into meaningful categories of words with shared semantic fields in a process analogous to the development of a coding scheme for the interpretative qualitative analysis of text. Interpretive researcher input is thus required to a certain extent in certain steps of the analysis, as the "lemmas" or categories in the classification of words with a similar meaning are constructed by the researcher. Nevertheless, using this technique makes the analysis more inductive than a purely qualitative analysis, as the researchers construct the categories after the identification of the word and production of the word list.

Lexical analysis is based on an innovative approach to using software originally designed for "corpus linguistics analysis" (CL) (e.g., Adolphs et al. 2004; Seale et al. 2006). Corpus linguistics is the analysis of large collections of stored, naturally occurring texts, and is typically used to examine discourses, that is, to examine texts as the representation of a certain world view or perception. This type of analysis has been used as an effective approach for quantitative analyses of large volumes of texts in the traditional media (Tesch 1990; Leech 1992; Gabrielatos and Baker 2008), as well as postings on social media like Twitter and web fora (e.g., Seale et al. 2006). Lexical analysis has also been proposed as a suitable method for analyzing qualitative textual data (e.g., Ryan and Weisner 1996; Jehn and Doucet 1996, 1997), as it is more inductive than conventional qualitative approaches. It seems, however, to be especially suited to the conjoint qualitative (thematic) and quantitative analysis of large bodies of texts (e.g., Seale et al. 2006; Gabrielatos and Baker 2008).

One key concept in lexical analysis is the notion of collocates. Collocates are two or more words that regularly co-occur. In this study we focus on the collocates of the NSI, which we define as all words appearing in the selected posts (as all selected and analyzed posts contain a reference to the NSI). All the words examined and the resulting word lists are thus collocates of the NSI. Many of those are an evaluative expression. In the context of lexical analysis, the examination of collocates can not only provide a "semantic analysis of a word" (Sinclair 1991, 1156-116) but also contributes to revealing its attributed meaning (e.g., Nattinger and DeCarrico 1992).

An analysis of collocates reveals the attitude or perception expressed (Gabrielatos and Baker 2008), in this case about the NSI. These attitudes and perceptions are subjective in nature. The aspect of subjectivity is taken into account in lexical analysis by making clear that the frequent use of particular collocates may result in particular meaning attributes being associated with the NSI that may be subjective and are not necessarily elements of 
the NSI's nature (Gabrielatos and Baker 2008). Moreover, words that at a first glance may seem descriptive can also be used in an evaluative way (be it positive or negative). This is an important notion, because in this study we are not interested in objective descriptions of the NSI, its surveys, the survey questionnaires, and the official statistics, but in the subjective perceptions and sentiments that the "speakers" have of these. Collocates thus provide information on the most frequent ideas associated with an entity or phenomenon; for example, our lexical analysis shows that the NSI is associated, among other things, with technical issues and "having to".

For the lexical analysis, the software program Concordance was used (see, www.concordancesoftware.co.uk/). The Concordance tool allows researchers, among others, to count words, cluster words into categories, and view and sort collocates. This software tool allows a more inductive approach to the formulation of coding categories than some other text analysis programs (e.g., Pennebaker et al. 2001) that rely on prespecified categories. In this project, the Concordance software was preferred over another frequently used tool, the WordSmith Tool, as the latter is primarily used to calculate keywords in texts on the basis of comparing the corpus with a reference corpus, which we did not have in this study.

In a second step, following the lexical analysis, we carried out a thematic (discourse) analysis. In this step the sentiment of the posts (positive/negative/neutral) as well as the themes or topics present in the posts were coded (e.g., Ryan and Bernard 2003; Braun and Clarke 2006). In line with Silverman's (2000) definition of a "text", discourse analysis focuses on how different versions of the world are produced through the use of a discourse. Accordingly, we were interested in the representations of $\mathrm{SN}$ as displayed in the postings we analyzed.

We made the decision to make our interpretation and coding scheme as objective as possible. Concerning the sentiment of the posts, the requirement for a post to be coded as negative was that the post contained a clear and objectively definable word or sentence as indicator of a negative evaluation of SN or a survey or something else "sent out" by SN (e.g., a survey, a reminder, a telephone call). For example, "failure", "bad", "®", "Aargh", and so on, are indicators for negative sentiments. The same holds for the positive sentiment, and includes indicators like "-)", "good news".

The complete set of posts was coded three times by one of the researchers. Between the second and the third coding round, the second researcher coded a subsample of the set, after which differences were discussed and the coding adapted. As with the collocates, themes could be descriptive as well as have evaluative meanings.

In the following section we describe the results of the analysis.

\section{Results}

\subsection{Exploring the Social Media}

In terms of the number of posts in the three-and-a-half year period and the number of different authors, the amount of the communication related to the NSI and business surveys on social media is not great (Table 1). Relative to the total numbers, very few posts about official business surveys are to be found in social media and on web forums: 
Table 1. Number of posts, words and authors in the analyzed dataset

\begin{tabular}{lc}
\hline & Number \\
\hline Posts & 477 \\
$\quad$ of which retweet or other kind of "repost" & $91(19 \%)$ \\
Words & 19,257 \\
Without stop words* & 3,513 \\
Authors & 378 \\
\hline
\end{tabular}

* Stop words are usually frequent words like "the" that are not meaningful.

477 posts are relevant. Furthermore, of these eligible posts a large number was "retweeted" or otherwise re-sent: 19 percent of the total number of posts is a "repost" of a former post by someone else, or of a news item. The vast majority of these posts are posted by different authors: on average an author posted 1.3 posts.

When looking at these posts over time, at first sight no clear structural annual fluctuations are visible, nor is there any relationship with survey contacts (Figure 1), for example there is no relation to when advance letters were sent out. There is one peak that stands out especially and which we could find an explanation for, namely January 2012. This peak was caused by a press release including a social media post by a Dutch ministry, stating that the administrative burden imposed on entrepreneurs by the NSI had decreased,

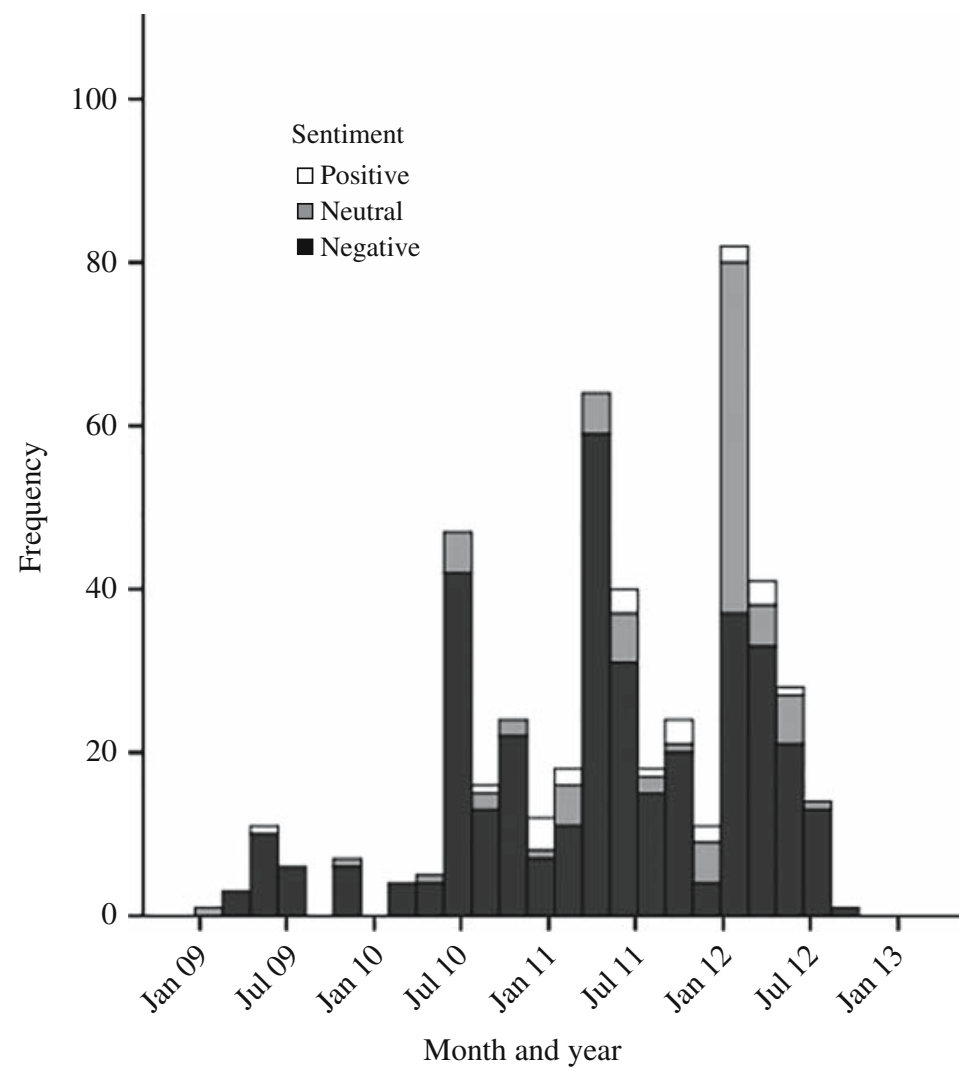

Fig. 1. Number of posts over time 
which was neutral in its presentation. This press release resulted in a large number of posts, including a large number of reposts by many different authors. Figure 1 also shows the sentiments of posts over time. The peak in January 2012 mainly consisted of neutral posts (43), followed by 26 negative posts, and only two positive posts. Most of these posts were coded as neutral as they were a straight repost of the original social media post by the Dutch ministry, without adding any positive or negative evaluations.

The largest number of posts in our selection were placed on Twitter (383), followed by Facebook (22 posts). It is important to note that possibly many posts on Facebook are not public, while we only had access to public posts. Conversely, tweets are all public by default.

\subsection{Results of the Lexical Analysis}

The results of the word count or "lexical analysis" are shown in Tables 2 and 3. Table 2 shows the prevalence of words that were among the query words in the Coosto database search. Table 3 shows meaningful words occurring most frequently that were not query words. This table conveys a picture of evaluative meanings that are associated with the NSI in the posts under study, that is, the collocates, and thus of the perceptions the authors of the posts have of the NSI. It is not surprising that in these posts the NSI is associated with "entrepreneurs", "filling in" questionnaires, "data", "statistics", and so on, as these are aspects that are part of the objective, factual role of the NSI in society. These thus can be seen as descriptive aspects that are not the core of our interest.

However, we also see the NSI being associated with other aspects that are not necessarily part of its factual definition. These are thus evaluative meanings attributed to the NSI, which are indicators of the perception and sentiments of the authors. It is these perceptions and sentiments we are interested in. In the following, we list these, clustered for a number of themes, giving examples only for the cases that complement the results of the thematic analysis (as will be discussed in the next subsection):

Technological issues ("software and hardware tools") and "failure" (in the two first examples together in one post):

"What a \#failure. The mandatory survey that you have to fill in as an entrepreneur doesn't function with that browser."

"Grrrr. ... Obliged to share information with the NSI but have been trying for already 2 months just to open the corresponding programme. \#fail”"

Table 2. Most frequently occurring query words in the analyzed dataset

\begin{tabular}{lc}
\hline Item & Number \\
\hline NSI & 607 \\
Questionnaire & 347 \\
Obligation & 229 \\
Letter & 85 \\
Fine & 56 \\
SBS & 50 \\
Threatening letter & 18 \\
\hline
\end{tabular}


Table 3. Most occurring meaningful words or categories of words in the analyzed dataset (excluding the query words of Table 2)

\begin{tabular}{lclc}
\hline Item & Number & Item & Number \\
\hline Fill in, supply, provide & 335 & "Again” & 58 \\
Negation & 329 & Annual report & 50 \\
Software or hardware tools & 215 & Research & 49 \\
Time period & 152 & Receive (a request) & 48 \\
Entrepreneurs & 146 & Failure & 47 \\
Data, information, figures & 137 & Statistics & 34 \\
Must, have to & 136 & "Time" & 31 \\
Sanctions & 136 & Threat, coercion & 30 \\
$\quad$ (of which "fine"*) & 56 & Report & 29 \\
Internet, internet tools & 103 & Netherlands & 28 \\
Government & 86 & Accountancy & 24 \\
Decrease, less & 66 & Economics & 22 \\
Question & 66 & "Cost", "costs" & 20 \\
& & Administration & 20 \\
\hline
\end{tabular}

* Quotation marks indicate a precise word as opposed to a category of words with similar meaning.

"It is possible to file a complaint but the term to receive an answer is 6 weeks. What do you mean, I'm an organization that is busy only with herself. \#NSI\#fail."

"Right. You receive an NSI survey that is obligatory, and then it does not function. Big \#fail.”

Coercion ("threat and coercion", "sanctions") is highly represented in the data.

We see as well that negations are overabundant in the posts, especially as opposed to "yes" or variations of that word (91 occurrences). Detailed scrutiny reveals that they concern a variety of issues of which we give two examples here. In the next section we will explore the issues related to negative feelings more deeply.

"This is sick. If you do not return your data in time to the NSI you're fined to up to $X € !$ Nutcase” (negation in relation with sanctions)

"You cannot fill in surveys of the NSI with browser X. What a fuss." (negation in relation with technological issues)

"Time" and denotations of time periods, such as "month", "year" or "week" are frequently used by business respondents on social media in combination with the NSI. This gives an impression of how important time is for businesses. Among the time periods we see the months January, March, April and July appear. These coincide with the dispatching of survey requests. The references to "time" are two sided: we find posts that talk about a decrease in time spent on the NSI's surveys, but others express experiencing the filling of the questionnaires as a waste of time.

Costs are referred to as costs in time but also as money spent on completing the NSI's questionnaires.

The word "again" shows us that the NSI is associated with reiteration. After a detailed scrutiny of these posts, it turns out that the authors of these posts experience contacts with 
the NSI as overly frequent. They refer not only to the advance letter and many survey requests, but also to the reminders.

"Pfff again the obligatory exercise for the NSI."

"Every time again these *** NSI questionnaires. . ."

Lastly, there are many references to "decrease" or "less". These concern posts that talk about a decrease in the administrative burden caused by the NSI.

\subsection{Thematic Analysis: Sentiments and Themes}

Next, we were interested in the themes present in the posts from a qualitative thematic perspective, and the sentiments expressed: positive, negative, or neutral. The majority of the posts express a negative sentiment (362 or 76 percent), followed by neutral posts (92 or 19 percent). Posts that express a positive sentiment are a minority and only number 23 (5 percent). The fact that there are more negative than neutral or positive posts could be due to the fact that people might be more prone to post something on the web when they have negative feelings than when they have neutral or positive feelings. These percentages are thus not representative of the feelings of the whole population of Dutch business respondents. However, by carefully examining the content of the posts we can infer reasons for these feelings and perceptions. In this section we present the themes found in the posts by sentiment. As Tables 4, 5, and 6 show, the content of the posts clearly diverges for the three kinds of sentiments. This divergence indicates that the respective themes show causes of positive, negative, or neutral feelings. The tables show which themes are related to these sentiments.

Table 4. Major themes in negative posts

\begin{tabular}{lcc}
\hline Theme & Number & Percentage* \\
\hline Questionnaires** & 285 & 79 \\
Statutory obligation & 186 & 51.4 \\
Technical problems & 102 & 28 \\
Unfamiliarity & 101 & 28 \\
Letter & 81 & 22 \\
Fine, sanctions & 74 & 20 \\
Coercive tone & 51 & 14 \\
Waste of time, costs in time & 42 & 11 \\
Difficult questionnaire & 35 & 10 \\
Many questionnaires & 29 & 8 \\
Unnecessary regulation & 28 & 8 \\
Tenacity & 24 & 7 \\
Long questionnaire & 25 & 7 \\
Lack of communication & 17 & 5
\end{tabular}

* Percentage (out of the 362 negative posts) of occurrence of the theme. As the table shows, most posts contain several themes.

** The themes not printed in italics are themes which overlap with search words and are present in the posts with all three sentiments. These are therefore considered to be less significant. 
Table 5. Major themes in neutral posts

\begin{tabular}{lcc}
\hline Theme & Number & Percentage* \\
\hline Questionnaires** & 45 & 49 \\
Administrative burden (decrease) & 39 & 42 \\
Statutory obligation & 38 & 41 \\
Unfamiliarity & 31 & 34 \\
Less costs in time & 9 & 10 \\
Letter & 9 & 10 \\
Fine, sanctions & 7 & 8 \\
Less costs in money & 6 & 7 \\
\hline
\end{tabular}

* Percentage (out of the 92 neutral posts) of occurrence of the theme. As the table shows, most posts contain several themes.

** The themes not printed in italics are themes which overlap with search words and are present in the posts with all three sentiments. These are therefore considered to be less significant.

In Tables 4, 5 and 6, the percentages indicate what percentages of posts contain the respective theme. Several themes can be present in one post at the same time. Themes not printed in italics are considered to be less important. The reason for this is that these themes contain search words and are present in the posts with all three sentiments. It is obvious that when you look for a certain theme, this theme will be present in your search results. On the other hand, if these search words are clearly differentially represented in the postings with different sentiments, then they can be an indicator of what influences the sentiment. The theme "failure of the NSI" is also present in the posts, but is not presented in this section as it was already covered above in the results of the lexical analysis.

\subsubsection{Themes in Negative Posts}

Table 4 shows the major topics that are identified in posts with a negative sentiment. Below we sum up the main causes of negative sentiments that are revealed and quote some exemplary posts. As these examples show, most posts contain several themes at once.

A significant portion of the posts that express a negative sentiment refers to technical problems, namely problems with software and/or hardware (e.g., the questionnaires cannot be completed in certain internet browsers). In particular, the combination of these technical problems with the fact that responding is mandatory appears to have resulted in negative sentiments.

Table 6. Major themes in positive posts

\begin{tabular}{lcc}
\hline Theme & Number & Percentage* \\
\hline Questionnaires** & 18 & 78 \\
Statutory obligation & 8 & 35 \\
Simplification questionnaires & 6 & 26 \\
Positive value of statistics & 4 & 17 \\
Administrative burden (decrease) & 3 & 13 \\
Decrease in amount of questionnaires & 3 & 13 \\
\hline
\end{tabular}

* Percentage (out of the 23 positive posts) of occurrence of the theme. As the table shows, most posts contain several themes.

** The themes not printed in italics are themes which overlap with search words, are blended and are present in the posts with all three sentiments. These are therefore considered to be less significant. 
"How tragic: the site of the survey of the NSI - which I'm legally obliged to fill in only works with internet browser X. \#bunglers \# government"

"I received a survey from the NSI which I'm legally obliged to complete, but can't be downloaded on X [hardware]. \#inwhatyeararetheylivingin?"

A lot of negative posts show that respondents are unfamiliar with the NSI, its role in society, the legal obligation to comply and the reasons for receiving the questionnaire. This unfamiliarity seems to make respondents insecure about their position. This seems to cause negative sentiments in combination especially with the receipt of a letter in which one is "threatened" with a fine.

"Oops, the NSI! What a nasty threatening letter. Since when am I legally obliged to hand in statistical data? \#sanctions (civil servants open until 17h)."

"Why am I LEGALLY MANDATED to supply company data to the NSI and otherwise the fine will be up to $x x x €$ ? \#daretoask"

As the posts also show, the letters that mention the possibility of fines are experienced as intimidating. Moreover, the coercive tone is expressed not to have a positive influence on the motivation and response behavior.

“@X1@X2 Last month I also had such a letter. Badly formulated and compelling, while they don't even explain why \#nsi”

"Another of those coercive letters by the NSI about obligatorily filling in the survey on X. Legal sanctions, fine, hell and damnation"

"Just filled in an NSI survey about my company. A task to seriously procrastinate. Probably the threatening letter has a role in that. . \#dig my heels in."

The lack of communication with the NSI may additionally cause negative sentiments when the help desk is hard to reach for business respondents who have a question.

"\#NSI survey, how much time would that cost? Could that be 2 days being unreachable by phone \& more than 10 minutes waiting time? And then I still have to fill it in . . ..; (“"

"But the online NSI questionnaire doesn't function. Telephone waiting time 15 minutes! A shame!”

"Ooooh yes, I am obliged to return the questionnaire by the 11th, but questions by email are only answered after 10 working days because of busyness !!! \#fail\#NSI"

Taking together all the above, the combination of the fine, the coercive tone, the tenacity, the deadline, the lack of communication, and the technical problems seem to additionally cause negative sentiments, and reinforce these.

"Great. The NSI OBLIGES me to fill in a questionnaire, or else. . fine. When I want to do this, I get an error message. So then, tell me how I should do this?"

"The NSI is stalking me with some survey and is threatening with sanctions, but in the meanwhile their own online survey questionnaire isn't functioning: \#notdoingwell." 
Completing official statistics' questionnaires is expressed to be experienced as a waste of time. Presumably the reason for this is that entrepreneurs prefer to spend their time on profit-oriented activities, and that they are unaware of the background of the NSI and its surveys.

"What a f** survey from the \#NSI, costs so much time to fill in, as like if I have nothing better to do."

"NOOOOOO, NSI has made up a new survey and we have to fill that in. \#Redtape. Want to work instead of filling in NSI surveys."

"Obliged to complete that survey!. . . . . WASTE OF MY TIME!!!!!!!!!!!!!!!!!!! With your vague letters!"

In addition, characteristics of the questionnaires, like questionnaires that are hard to complete, long questionnaires, and the fact that businesses receive many questionnaires (for various surveys or as part of a recurring survey) are also found as a cause of negative sentiments.

"Filled in an NSI survey on the internet. Jesus, what a user-unfriendly survey was that pfff * completely irritated $*$ ”

“@x. It also cost me a full afternoon and a pot of diazepam to fill in that \#NSI bunch of misery. I ate the threatening letter $\odot$ ")

"\#NSI is giving me the itches. On an average I receive 10 surveys a month. . ."

Some negative posts refer to the large number of legal requirements entrepreneurs have to respect. The legal obligation to respond to the NSI's business surveys is seen as one of these, and experienced as an "unnecessary control mechanism".

"Filling in the obligatory NSI questionnaire costs hours with those technical problems. Nonsense rules; \#NSI \#government \#wasted tax money \# fail.”

"I've had my own company for 22 years now and have wasted at least 60 percent of my time complying with rules of the municipality, province, state and some more of these scumbags. And don't forget filling in surveys of the NSI among others. I'll become a communist as well very soon. I don't think it will make a huge difference in this country."

\subsubsection{Themes in Neutral Posts}

Even though the neutral posts do not clearly express a positive or negative sentiment, they identify themes that denote business respondents' concern or interest. Besides, they also reflect the perceptions of the authors of the posts. Most of these posts are reposts or retweets, indicating that at least the authors somehow find it worthwhile to make others aware of the message. The main themes in neutral posts, apart from the search words as shown in Table 5, refer to administrative burden (39), and unfamiliarity with the NSI (31), indicating that these issues have the attention of business respondents.

The posts below are examples of neutral posts. We decided to code these as neutral as no clear and objectively definable word(s), symbol(s) or sentence as indicator of a negative 
evaluation of Statistics Netherlands or its surveys are present in these posts, like "\#fail", "bad", “:", "Aargh", and so on.

\section{Administrative burden:}

"Administrative burden on entrepreneurs by the NSI decreases."

\section{Unfamiliarity:}

"Ooops I didn't know that as a company you're legally obliged to supply data if the NSI asks for that, so just decided to do that... ."

"If I don't cooperate with a survey, there will be consequences?? Since when is it compulsory to fill in a survey?"

"Today I received a letter by the NSI. I must COMPULSORILY cooperate in a study into the business environment. Is that really possible just like that?"

\section{Less costs in time:}

"NSI surveys are costing entrepreneurs less time: the administrative burden for entrepreneurs..."

\section{Letter:}

"Letter from the NSI: the government considers the providing of data that important that they have made it legally obligatory"

\subsubsection{Themes in Positive Posts}

Themes in positive posts are shown in Table 6. These include the simplification of the questionnaires, the acknowledgment of the value of statistics produced by the NSI, the decrease of the administrative burden, and the observation that the number of questionnaires is being reduced. Examples of these posts are:

\section{Simplification:}

"Then there's good news. The NSI reduces and simplifies the surveys for one-man companies and SMEs.”

\section{Positive value of statistics:}

"Just completely filled in a long questionnaire on request by the NSI. That's good for the accuracy of the statistics. \#you'rewelcome."

\section{Decrease administrative burden:}

"\#goodnews: Administrative burden for entrepreneurs by the NSI decreases."

\section{Decrease in amount of questionnaires:}

"Good news for one-man companies, less surveys by the NSI to one-man companies." 


\section{Conclusion and Discussion}

\subsection{Exploring and Analyzing Social Media Data}

The exploratory study presented in this article is - to the best of our knowledge - one of the first on the use of social media data aimed at exploring the perception and sentiments of business survey respondents. Based on our findings and experience we can suggest the following recommendations toward conducting social media studies on survey respondents.

As discussed in the introduction, the large share of the noninformative "babble" messages on social media negatively affects the use of the more serious informative messages (Daas et al. 2013). It is thus very important to make an appropriate selection and to define the relevant keywords and synonyms (as used by the target population) to use for the query. When the target population is not well defined, posts from units that are out of scope may be selected, resulting in overcoverage of the posts. This is important as the number of data records will be vast. On the other hand, when keywords are missed, the data set may not cover all eligible posts, resulting in undercoverage of posts. As Stieglitz and Dang-Xuan $(2012,1283)$ state: "to attain a high level of data completeness, relevant keywords representing the topic of interest have to be carefully and systematically chosen in advance".

The characteristics of social media data also have implications for the analysis methods that should be used. As discussed in Subsection 2.2, we applied a two-step mixed-method design, including both a word count and a thematic analysis. As for the thematic analysis, posts were coded several times by one of the authors and a sample was coded by both authors. This was done to achieve intra- and intercoding reliability.

The two methods used in this two-step mixed-method approach can help triangulate their respective findings (e.g., Baker et al. 2008, 295). Triangulation is a method used by qualitative or mixed-methods researchers to check and establish validity in their studies by analyzing a research question from multiple perspectives (Guion et al. 2011). However, our two chosen methods are also complementary: with the lexical analysis we were able to identify themes we would not have found with the thematic analysis and vice versa. The lexical analysis in the first step aided the identification of themes and coding of the posts, as it showed quantitative evidence of words and patterns being used repeatedly (e.g., Hardt-Mautner 1995; Baker et al. 2008), and aided in the identification of areas of interest (e.g., Mautner 2007). In this way it helps to safeguard against over- or underinterpretation. The thematic analysis in the second step has the advantage that one can look beyond the semantic level, and themes can be coded at the latent level. Also, so-called wider themes (Gabrielatos and Baker 2008) or metathemes (Ryan and Bernard 2003) can be identified. Subtle, implicit meanings cannot be easily analyzed through lexical analysis (Wodak 2007), but can be identified with qualitative thematic coding. One example in the case of this study would be the unfamiliarity with the NSI frequently referred to in the postings. We were only able to identify this theme when we did the thematic coding. If we had only done the lexical analysis we would not have identified this theme. 
The representativeness of social media data is still an issue, but recent findings are positive. Daas et al. (2013) discuss opportunities and challenges associated with using social media data from the Coosto database for official statistics based on a case study conducted at Statistics Netherlands. They found that the monthly sentiment for the period June 2010 to August 2012 derived from Dutch social media messages taken from the Coosto database correlated very strongly $(0.83)$ with the officially determined monthly Dutch consumer confidence. In addition, it also correlated with the sentiment for the subindicator of the attitude towards the economic climate (0.88). This high correlation is remarkable, as the populations from which the data are obtained are different: both official indicators are based on a sample survey in which 1,500 people are interviewed each month.

\subsection{Summary and Discussion of the Analysis Results}

We found that the discussions on social media with regard to the NSI, its surveys and questionnaires are very small in number. The number is small both relative to the total number of public posts and relative to the total number of questionnaires dispatched every year. Furthermore, we did not find important annually reoccurring increases in communication activities related to the dispatching of questionnaires.

The topics discussed show a variety of themes, varying over the associated sentiments: negative, positive, and neutral. In negative posts the main themes are: technical failures; unfamiliarity with the NSI and its role; letters that are perceived as too coercive; the idea that filling in a questionnaire is a waste of time and that these surveys are "unnecessary mandatory regulations"; characteristics of the questionnaire and the inaccessibility of the NSI for business respondents with questions, both by telephone and email. In a number of posts more than one theme was mentioned, indicating that especially a combination of these aspects may lead to negative feelings. The combination of the technical problems with the waiting time to contact the NSI, the legal obligation to comply and the strict deadlines to return the completed questionnaire, is not helpful in establishing a positive perception of the NSI.

A positive image is associated with the simplification of questionnaires, the positive value of official statistics and the (perception of) a decrease of the response burden.

Neutral posts indicate that entrepreneurs somehow show an interest in the reduction of response burden, simply by retweeting messages about this topic. The neutral posts also show, like the negative posts, that some business respondents are unfamiliar with the NSI, from which we can conclude that this is an important topic to address.

Considering the attention that is given to the imposed response burden by SN, by politicians and in various publications by, for example, business organizations, commercial banks, as well as the government, we had expected that this topic would also be discussed quite often on social media. However, this assumption is not corroborated by our exploratory analysis. This may have several reasons. The findings may indicate that a vast majority of entrepreneurs is not as interested in posting on this topic on social media as we thought. Possibly they are too busy running their businesses to spend much time communicating on social media about these issues. It is also possible that the topic in itself is not as important to them as we thought. This might 
also be a reason why we did not find important annually reoccurring increases in communication activities related to the dispatching of questionnaires. However, we still need to put some critical remarks with these data and the analyses. We only had access to public posts; private posts are not included in our database. This may lead to an underestimation of the number of messages in our source.

Nevertheless, we can validate our conclusions. We can conclude that in the overall picture, the findings (as to the expressed sentiments) are in line with findings from previous qualitative and quantitative studies on sentiments of business respondents towards SN and its surveys. Giesen (2012) analyzed the results of the Customer Satisfaction Survey conducted by SN in 2006. In this survey, a sample of respondents of the Dutch Structural Business Survey (SBS) was contacted for a short CATI interview asking questions about the completion of the SBS questionnaire and the respondents' opinion about SN. As an indicator of the overall attitude towards SN, a question is used which asks respondents to rate their overall satisfaction with $\mathrm{SN}$ with a grade between 1 and 10. On average respondents grade $\mathrm{SN}$ at 6.5. According to the Dutch system of rating school grades this would be slightly above satisfactory. 13 percent of the respondents give a grade below 6, an unsatisfactory grade. In Snijkers et al. (2007), qualitative data show that negative sentiments are related to: costs; the statutory obligation; the fines; threats and tone of the letters; and lack of knowledge of survey procedures (especially the importance of random sampling). Interest in and usefulness of the survey topic is another important topic: businesses generally did not rate surveys as useful for society or themselves. Also unfamiliarity is found. Customer-friendliness, on the other hand, is associated with positive sentiments.

Following on from these studies, with this analysis we have gained additional quantitative information about perceptions of business respondents of official surveys. More importantly, we have gained information about causes for a positive or negative perception, and aspects that are related to positive or negative sentiments. This analysis is an inductive and empirical observation of existing perceptions and sentiments about the NSI and its surveys and causes for these perceptions and sentiments. The breakdown of the sentiments in percentages may not be representative of the breakdown in percentages of the whole population of business respondents in the Netherlands, but that is not the main and most important finding of the analysis.

The analysis shows which actions taken by the NSI and which features of the communication and survey design are related to the expressed perceptions and sentiments. Therefore, the results give an empirical indication of how the communication and survey design could be adapted to positively influence survey response (Figure 2).

\subsection{Recommendations for Survey and Communication Design}

Based on the results, we can formulate a set of recommendations that should eliminate the causes of negative sentiments, enhance a positive perception of the NSI and its surveys, and therefore enhance motivation to comply and increase response rates and the quality of the response. These recommendations follow and corroborate the recommendations of previous studies (for example Snijkers et al. 2007; Torres van Grinsven et al. 2011, 2012). 
They also are in line with internationally identified factors affecting the business survey response process (Snijkers et al. 2013).

As costs in time and money are important for entrepreneurs, it is important to reduce participation costs but also to increase the (perceived) value, or the (perceived) benefit, of the surveys for the businesses. This is in line with social exchange theory (Homans 1958), which when applied to survey behavior asserts that the actions of respondents in answering a questionnaire are motivated by the personal benefit these actions are expected to bring, or usually do bring. Whether a given behavior occurs is a function of the perceived costs of engaging in that activity and the expected rewards (Poon et al. 1999). Social exchange theory has been applied extensively to improve survey participation in the field of household surveys (e.g., Dillman 1978). Singer (2012) proposes a variant of this theory the benefit-cost theory, in which the argument is that people choose to act when the benefits of doing so outweigh the costs in their subjective calculation.

Along the same line, it is very important to facilitate and simplify the response tasks to reduce (perceived) costs. Initial perceptions of high costs and negative experiences cause a negative perception and therefore a higher perceived burden (Giesen 2012), especially in combination with a coercive tone, the strict response deadline, and response chasing. The NSI should also make clear to business respondents that it has made efforts to facilitate the response process. Furthermore, our analysis shows that simplification of questionnaires enforces positive sentiments, which may lift the public image of an NSI.

Besides, the unfamiliarity with the NSI, its role as surveyor of data and producer and publisher of statistics needs to be marketed by developing a sound and coherent survey communication strategy (see also Snijkers 2009).

A final set of recommendations is related to the use of social media as a communication channel to be used by NSIs. Social media can be used to disseminate statistics, but can also be used to communicate with respondents and as a channel in a communication strategy to enhance a positive perception (see, Figure 2).

Current theories within linguistics claim that people are unconsciously primed to infer meanings due to the cumulative effect of all of their previous encounters with a word, that is, the collocates of that word (e.g., Hoey 2005). This means that if people in the media

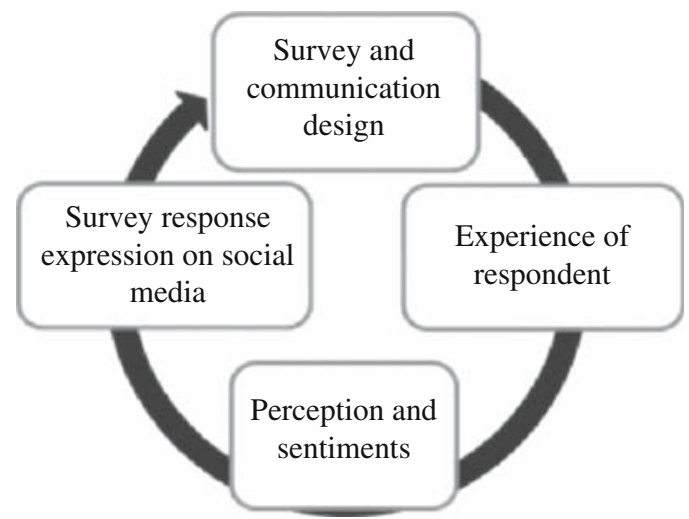

Fig. 2. Communication strategy and sentiments of respondents 
consistently come across the NSI in combination with burden, they are primed to associate the NSI with burden. Therefore it is important for statistical bureaus to consciously engage in well-considered communicative practices to influence the perception that people and business respondents have of the statistical bureau, and evaluate the effectiveness of these practices. Social media, together with traditional media, can be used to actively and pervasively inform the public and businesses about the NSI, its role and importance in the modern information society, and consequently influence the perception and image business respondents and the public in general have of an NSI. Social media can also be used to monitor the effectiveness of these communication activities.

\section{References}

Adolphs, S., B. Brown, R. Carter, P. Crawford, and O. Sahota. 2004. “Applying Corpus Linguistics in a Health Care Context.” Journal of Applied Linguistics 1: 9-28.

Baker, P., C. Gabrielatos, M. Khosravinik, M. Krzyzanowski, T. McEnery, and R. Wodak. 2008. "A Useful Methodologic Synergy? Combining Critical Discourse Analysis and Corpus Linguistics to Examine Discourses of Refugees and Asylum Seekers in the UK Press." Discourse and Society 19: 273-306. Doi: http://dx.doi.org/10.1177/ 0957926508088962.

Blumer, H. 1973. Symbolic Interactionism: Perspectives and method. Prentice-Hall, Englewood Cliffs: New Jersey.

Braun, V. and V. Clarke. 2006. "Using Thematic Analysis in Psychology." Qualitative Research in Psychology 3: 77-101. Doi: http://dx.doi.org/10.1191/1478088706qp 063oa.

Coosto. 2014. The Facts Webpage. Available at: http://www.coosto.nl/home/about/feiten and in English at http://www.coosto.co.uk/home/about/facts (accessed March 2014).

Daas, P.J.H. and M.J. Puts. 2014. "Social Media Sentiment and Consumer Confidence. Statistics Paper Series, No. 5. European Centeral Bank.” Available at: http://www.ecb. europa.eu/pub/pdf/scpsps/ecbsp5.pdf (accessed April 16, 2015).

Daas, P.J.H. and M.J. Puts. 2014a. "New and Emerging Methods: Big Data as a Source of Statistical Information.” The Survey Statistician 69. Available at: http://isi.cbs.nl/iass/ N69.pdf (accessed April 16, 2015).

Daas, P.J.H., M.J. Puts, B. Buelens, and P.A.M. van den Hurk. 2013. "Big Data and Official Statistics." In Proceedings of the NTTS (New Techniques and Technologies for Statistics) 2013, March 5-7, Brussels. Available at: http://www.cros-portal.eu/sites/ default/files/NTTS2013fullPaper_76.pdf (accessed April 16, 2015).

Daas, P.J.H., M. Roos, M. van de Ven, and J. Neroni. 2012. “Twitter as a Potential Data Source for Statistics.” Discussion paper 201221. The Hague/Heerlen: Statistics Netherlands. Available at: http://www.cbs.nl/NR/rdonlyres/04B7DD23-5443-4F98B466-1C67AAA19527/0/ 201221x10pub.pdf (accessed April 16, 2015).

Dillman, D. 1978. Mail and Telephone Surveys: The Total Design Method. New York: John Wiley and sons.

Gabrielatos, C. and P. Baker. 2008. "Fleeing, Sneaking, Flooding: A Corpus Analysis of Discursive Constructions of Refugees and Asylum Seekers in the UK Press 
1996-2005." Journal of English Linguistics 36: 5-38. Doi: http://dx.doi.org/10.1177/ 0075424207311247.

Giesen, D. 2012. "Exploring Causes and Effects of Perceived Response Burden.” Paper presented at the Fourth International Conference on Establishment Surveys (ICES IV), Montreal, 11-14 June, 2012. Available at: http://www.amstat.org/meetings/ices/2012/ papers/302171.pdf (accessed April 16, 2015).

Groves, R.M. 2011. “Three Eras of Survey Research.” Public Opinion Quarterly 75: 861-871. Doi: http://dx.doi.org/10.1093/poq/nfr057.

Guion, L.A., D.C. Diehl, and D. McDonald. 2011. Triangulation: Establishing the Validity of Qualitative Studies. Available at: http://edis.ifas.ufl.edu/fy394 (accessed June 1, 2014).

Haraldsen, G. 2013. "Quality Issues in Business Surveys.” In Designing and Conducting Business Surveys, edited by G. Snijkers, H. Haraldsen, J. Jones, and D. Willimack, 83-125. Hoboken, NJ: Wiley.

Haraldsen, G., J. Jones, D. Giesen, and L.-C. Zhang. 2013. "Understanding and Coping with Response Burden." In Designing and Conducting Business Surveys, edited by G. Snijkers, H. Haraldsen, J. Jones, and D. Willimack, 219-252. Hoboken: Wiley.

Hardt-Mautner, G. 1995. Only Connect. Critical Discourse Analysis and Corpus Linguistics. UCREL Technical Paper 6. Lancaster: Lancaster University. Available at: http://ucrel.lancs.ac.uk/papers/techpaper/vol6.pdf (accessed April 16, 2015).

Hoey, M. 2005. Lexical Priming: A New Theory of Words and Language. London: Routledge.

Homans, G.C. 1958. "Social Behavior as Exchange.” Americal Journal of Sociology 63: $597-606$.

Jehn, K.A. and L. Doucet. 1996. "Developing Categories from Interview Data: Text Analysis and Multidimensional Scaling. Part 1." Field Methods 8: 15-16.

Jehn, K.A. and L. Doucet. 1997. "Developing Categories for Interview Data: Consequences of Different Coding and Analysis Strategies in Understanding." Field Methods 9: 1-7.

Jensen, K.B. 2012. A Handbook of Media and Communication Research. Qualitative and Quantitative Methodologies, 2nd ed. New York: Routledge.

Jensen, K.B. and R. Helles. 2011. "The Internet as a Cultural Forum: Implications for Research." New Media and Society 13: 517-533. Doi: http://dx.doi.org/10.1177/ 1461444810373531.

Leech, G. 1992. "Corpora and Theories of Linguistic Performance." In Directions in Corpus Linguistics: Proceedings of the Nobel Symposium 82, Stockholm, 4-8 August 1991, edited by J. Svartvik, 105-122. Berlin: Mouton de Gruyter.

Mautner, G. 2007. "Mining Large Corpora for Social Information: The Case of Elderly." Language in Society 36: 51-72. Doi: http://dx.doi.org/10.1017/S0047404507070030.

Nattinger, J.R. and J.S. DeCarrico. 1992. Lexical Phrases and Language Teaching. Oxford: Oxford University Press.

Pennebaker, J.W., M.E. Francis, and R.J. Booth. 2001. Linguistic Inquiry and Word Count (LWIC): A Computerized Text Analysis Program. Mahwah, NJ: Erlbaum Publishers. 
Poon, P., G. Albaum, and F. Evangelista. 1999. "An Empirical Test of Alternative Theories of Survey Response Behaviour.” International Journal of Market Research 41: $1-18$.

Ryan, G.W. and H.R. Bernard. 2003. "Techniques to Identify Themes.” Field Methods 15: 85-109. Doi: http://dx.doi.org/10.1177/1525822X02239569.

Ryan, G.R. and T. Weisner. 1996. "Analyzing Words in Brief Descriptions: Fathers and Mothers Describe Their Children." Field Methods 8: 13-16.

Seale, C., S. Ziebland, and J. Charteris-Black. 2006. "Gender, Cancer Experience and Internet Use: A Comparative Word Analysis of Interviews and Online Cancer Support Groups." Social Science and Medicine 62: 2577-2590. Doi: http://dx.doi.org/10.1016/j. socscimed.2005.11.016.

Silverman, D. 2000. "Analyzing Talk and Text." In The Handbook of Qualitative Research, edited by N.K. Denzin and Y.S. Lincoln, 821-834. Thousand Oaks, CA: Sage.

Sinclair, J. 1991. Corpus Concordance Collocation. Oxford: Oxford University Press.

Singer, E. 2012. "Toward a Benefit-Cost Theory of Survey Participation: Evidence, Further Tests, and Implications." Journal of Official Statistics 27: 379-392.

Snijkers, G. 2008. "Getting Data for Business Statistics: A Response Model." Paper presented at the $4^{\text {th }}$ European Conference on Quality in Official Statistics, Rome. Available at: http://q2008.istat.it/sessions/25.html (accessed April 16, 2015).

Snijkers, G. 2009. "Getting Data for (Business) Statistics: What's new? What's next?" Paper presented at the 2009 NTTS Conference (New Techniques and Technologies for Statistics). Brussels. Available at: http://ec.europa.eu/eurostat/documents/1001617/ 4398389/S5P2-GETTING-DATA-FOR-STATISTICS-SNIJKERS.pdf (accessed April 16, 2015).

Snijkers, G., B. Berkenbosch, and M. Luppes. 2007. "Understanding the Decision to Participate in a Business Survey." In Proceedings of the Third International Conference on Establishment Surveys (ICES-III). 18-21 June, 2007. Alexandria, VA: American Statistical Association, 1048-1059. Available at: https://www.amstat.org/meetings/ ices/2007/proceedings/TOC.pdf.

Snijkers, G., R. Göttgens, and H. Hermans. 2011. "Data Collection and Data Sharing at Statistics Netherlands: Yesterday, Today, Tomorrow." Paper presented at the 59th plenary session of the Conference of European Statisticians, 14-16 June, 2011, Geneva. Available at: http://www.unece.org/fileadmin/DAM/stats/documents/ece/ces/2011/20. e.pdf (accessed April 16, 2015).

Snijkers, G., G. Haraldsen, J. Jones, and D.K. Willimack. 2013. Designing and Conducting Business Surveys. Hoboken, NJ: Wiley.

Snijkers, G. and J. Jones. 2013. "Business Survey Communication." In Designing and Conducting Business Surveys, edited by G. Snijkers, H. Haraldsen, J. Jones, and D. Willimack, 359-430. Hoboken, NJ: Wiley.

Stieglitz, S. and L. Dang-Xuan. 2012. "Social Media and Political Communication: A Social Media Analytics Framework." Social Network Analysis and Mining 3: 1277-1291. Doi: http://dx.doi.org/10.1007/s13278-012-0079-3.

Tesch, R. 1990. Qualitative Research: Analysis Types and Software Tools. New York: Falmar Press. 
Torres van Grinsven, V., I. Bolko, and M. Bavdaž. 2014. In Search of Motivation for Business Survey Response Task. Journal of Official Statistics 30: 579-606. Doi: http:// dx.doi.org/10.2478/JOS-2014-0039.

Torres van Grinsven, V., I. Bolko, M. Bavdaž, and S. Biffignandi. 2011. "Motivation in Business Surveys." BLUE-ETS Conference on business' burden and motivation in official surveys, Statistics Netherlands, March 22-23 edited by D. Giesen and M. Bavdaž. Available at: http://www.cbs.nl/NR/rdonlyres/23FD3DF5-6696-4A04B8EF-1FAACEAD995C/0/2011proceedingsblueets.pdf (accessed April 16, 2015).

Van Vroenhoven, J. 2006. "Storend!" In Humor om te huilen: Zwartboek doorgeslagen regelgeving, 22-23. Tilburg: Brabants-Zeeuwse Werkgeversvereniging (BZW).

Wenemark, M., A. Persson, H. Noorlind Brage, T. Svensson, and M. Kristenson. 2011. "Applying Motivation Theory to Achieve Increased Response Rates, Respondent Satisfaction and Data Quality." Journal of Official Statistics 27: 393-414.

Willimack, D. and G. Snijkers. 2013. "The Business Context and Its Implications for the Survey Response Process." In Designing and Conducting Business Surveys, edited by G. Snijkers, H. Haraldsen, J. Jones, and D. Willimack, 39-82. Hoboken, NJ: Wiley. Wodak, R. 2007. "Pragmatics and Critical Discourse Analysis: A Cross-Disciplinary Inquiry." Journal of Pragmatics and Cognition 15: 203-227. Doi: http://dx.doi.org/ 10.1075/pc.15.1.13wod.

Received August 2013

Revised January 2015

Accepted January 2015 